\title{
A Study of Convergence to Control the Cost of Concrete Bridges in the Design Stages in Yemen
}

\author{
Majed Al-Sebaeai ${ }^{a}$, Khalil Al-Bukhaiti ${ }^{\text {b* }}$, Shixiong Zheng ${ }^{\mathrm{b}}$ \\ ${ }^{a}$ School of Civil Engineering, south west Jiaotong University, Chengdu 610031, Sichuan, China. \\ ${ }^{b}$ School of Civil Engineering, south west Jiaotong University, Chengdu 610031, Sichuan, China.
}

Received 20 January 2018; Accepted 28 February 2018

\begin{abstract}
This research deals with the subject of concrete bridges projects cost control during the design phase. This research falls within the framework of the road bridges projects where cost control is used as a tool to help design and decision making.

The objective of this study is to develop a methodology to control the cost of bridge projects during the early design stages, by investing the database with any helpful software tool, the proposed cost control methodology is based on modeling the original elements and proposing a method of cost estimate based on the estimate of quantities from general parameters of origin and prices be updated periodically. The proposed methodology studies the various technical solutions chosen by the designer and evaluates them economically.

In this paper, a study was conducted on (12) bridges within the capital Sana'a bridges project and (7 bridges) those carried out in Sana'a-Aden road, by using the statistical program (SPSS) as a specialized program in this field, logical and theoretical issues have also been taken into account. Results that require us to study the design of the bridges based on a controlled database and applied to the case of cost and time, and on the impact of implementation risk on the cost of the project during the design phase, and the various models necessary to design a database structure that was enriched with information collected from different bridge projects were presented in the Republic of Yemen.
\end{abstract}

Keywords: Design Stages; Cost Control; Parameters Estimation; Concrete Bridges; SPSS.

\section{Introduction}

The bridges projects are one of the most critical projects that governments rely on in the development of infrastructure. These projects are part of the more massive project, the Roads Project. These projects are based on two types of data: original data derived from the environment in which they belong, and functional data drawing from the main project, which form part of it (longitudinal section, cross section etc.).

The road projects are often overlooked and other elements neglected, which explains some of the cost deviations that occur during the implementation of road projects, mainly if the road project includes numbers and essential types of bridges. During designing the road project with its complementary projects (bridges, tunnels), the cost control is not given the proper status within the design process, both regarding the period or the importance of the process. In fact, the cost control is often reduced to a rapid cost estimation process, which is guessed shortly before the tender is put forward, raising many questions about the validity of the decisions being made, especially regarding equal work such as bridges and tunnels.

This research attempts to give the bridges the position that deserves within the road project and proposes a cost

* Corresponding author: khali12020@my.swjtu.edu.cn

doi http://dx.doi.org/10.28991/cej-0309114

> This is an open access article under the CC-BY license (https://creativecommons.org/licenses/by/4.0/).

(C) Authors retain all copyrights. 
control approach that contributes to improving the decisions taken by the designers, which must keep pace with the design from the early stages until the completing all the design requirements.

The main aim of this work is to integrate optimization into the Structural design, considering investment cost and environmental Impacts. The present work is focused on the design of concrete slab Frame bridges. Yepes et al. (2012) used a hybrid multi-start optimization method based on the threshold acceptance strategy to investigate optimization of Reinforced concrete retaining walls. They attempted to find either the Minimum cost of the structure or minimum CO2 emissions. Their results Show that designs with low embedded emissions are very similar to the most cost-effective solutions Yeo and Potr (2013) applied an optimization method to achieve sustainable design of reinforced concrete frame structures under gravity and lateral loads while reducing $\mathrm{CO} 2$ emissions. Another application of optimization by Yeo and Gabbai (2011) included as design variables the width and height of a reinforced concrete beam and the total area of the longitudinal reinforcement. The objective function is either cost or total embedded energy of the reinforced concrete structures, accordingly, the structural optimization of bridges and reduction of their cost and environmental impacts are essential and should be taken into consideration for a sustainable bridge design in another application of structural optimization and automated design, Moharrami and Grierson (1993) presented a computerized method ("optimally criteria method"), for optimization of two-dimensional reinforced concrete building frameworks. In this method, the cross-section dimensions and longitudinal reinforcement that lead to the minimum cost of the structure are determined. Moharrami and Grierson (1993) have applied the aforementioned method in the optimization of two framework examples to show the features of this optimization method [1].

\subsection{Research Importance and Objectives}

The importance of research comes from treating the road bridges projects and focusing on the cost control which is one of the essential supports of entrepreneurship. As for road bridges, it has previously been found that they constitute an essential part of the road project and that they suffer from neglect.

This explains the existence of deviations in the cost proportional to the number and size of the bridge projects. This research attempts to rebalance the road project and try to draw attention to the necessity of considering the bridges projects while designing the road projects, especially during the early stages of design.

With respect to cost control that must accompany all phases of the project, the focus was on the cost control during the early design phases of since these phases are of utmost importance in determining the essential features of the bridge such as (bridge type, support type, slab type, type of protection equipment for vehicle...etc.) the cost control has also been employed within a comprehensive approach to help design and decision making.

Through this research, it is aimed to achieve the following objectives:

1) Developing a methodology to control the cost of the roads bridges projects during the early design stages based on an accurate project modeling and cost estimation tools.

2) Proposing a methodology to assist designing and decision-making by investing the database using a software tool.

\subsection{Literature Review for Study of Convergence to Control the Cost of Concrete Bridges}

The aim of structural optimization should encompass not only finding the cost-optimized structure but also introducing automation in the structural design process. Templeman (1983) studied the use of structural optimization software in design offices and tried to examine the benefits of implementing computational optimization methods into practice.

Referring to the lack of practical optimization software at that time, templeman recommends more cooperative efforts between researchers and design offices. The aim here should be developing user-friendly and proficient structural optimization software, focusing on practical design problems and establish more time and cost effective as well as more productive design procedures. Among the first efforts of computer automated designs, Aguilar et al. (1973) at the Louisiana State University, in collaboration with the Louisiana Department of Highways, developed a computer program for use in designing and optimizing highway bridges.

Their modular computer program allows the geometry of the bridge, soil conditions, construction costs and other parameters to be defined by the user. The authors claim that by using "dynamic programing" and heuristic optimization methods, the computer program can provide both preliminary designs and optimum and near optimum designs of multispan concrete bridges according to design specifications of the American Association of State Highway Officials (AASHTO) and the Louisiana Department of Highways.

In another application of structural optimization and automated design, Moharrami and Grierson (1993) presented a computerized method ("optimally criteria method"), for optimization of two dimensional reinforced concrete building frameworks. In this method, the cross-section dimensions and longitudinal reinforcement that lead to the minimum cost of the structure are determined. Moharrami and Grierson (1993) have applied the aforementioned method in the 
optimization of two framework examples to show the features of this optimization method.

Structural optimization of complex structures like bridges can lead to significant savings in the cost and design time. Cohn and Lounis (1994) presented an application of multilevel and multi-criteria optimization of structural concrete bridge systems. The focus of their research is prestressed concrete bridges with span lengths varying between 10 and 50 $\mathrm{m}$ and widths of 8 to $16 \mathrm{~m}$. The optimization proceeds at three levels: Level one, optimization of system components (e.g., cross-section dimensions, prestressed and ordinary reinforcement amount and layout, etc.)[3]. Level two, optimization of transversal and longitudinal system configuration of a bridge with a specific total length and width (e.g., number of spans, girder spacing, simple or continuous span or frame, etc.). Level three, optimization of structural system type (e.g., slab on precast I girders, solid or voided slab, one- or two-cell box girder). Level one of the optimization process uses nonlinear programming, and levels two and three apply a sieve-search process. The constraints are ultimate limit state (ULS) and serviceability limit state (SLS) requirements and design specifications according to Canadian and US bridge standards. The most important criterion in this multi-objective optimization is the minimum cost of the superstructure. Other objective functions, which introduced as "merit criteria", are minimum weight of prestressing reinforcement, minimum volume of concrete, maximum girder spacing, minimum superstructure depth, maximum span to depth ratio, maximum feasible span length, and minimum superstructure camber. These criteria are based on different situations, for instance, aesthetic aspects, lack of cost data, unknown specific code limitations, limited clear space, and full, partial or zero prestressing solutions, etc. The obtained results can be used in the preliminary bridge design to find the optimal structural system, longitudinal and transverse configuration, member's crosssection sizes, and prestressed as well as non-prestressed reinforcement layout and amount. Furthermore, Sirca and Adeli (2005) presented cost optimization procedure for precast, prestressed concrete I-beam bridge systems by using the robust neural dynamics model of Adeli and Park to solve a mixed integer-discrete nonlinear optimization [2]. The design constraints are based on AASHTO 1999 design specifications and the objective function consists of the cost of concrete, reinforcement, formwork, and manufacturing of the I-beams. In another work, Martí and Vidosa (2010) studied cost optimization of cross-sections of precast prestressed concrete pedestrian bridges by using simulated annealing (SA) and threshold accepting (TA) algorithms. Among the studies in cost optimization of bridge structures, the following works can also be mentioned: cost minimization of a prestressed concrete box bridge girder used in a balanced cantilever bridge by Yu et al. (1986); cost optimization of a continuous three-span bridge RC slab of $16.6 \mathrm{~m}$ span length by Barr et al. (1989) using the general geometric programming method; optimization of short and medium span highway bridges consisting of reinforced concrete slabs on concrete I-girders by Lounis and Cohn (1993); and optimization of prestressed concrete highway bridges by Torres et al. (1996) [1], [4]. In Mar 2014 K.Vamsidhar said to be successful when it is completed in desired time and cost. The construction delays are common problems in private residential projects in Chennai city. This problem occurs frequently during life time leading to dispute and litigations [5], and also Ahmad Jrade and Julien Lessard in 2015 they say The ITCMS is beneficial at the design stage; construction professionals are able to synchronize the building model with time and cost parameters as well as optimize it through a clash detection process that results in budget and schedule compressions early on. The ITCMS is a useful tool for construction and engineering managers that strive to increase projects' performance [6].

Renata Ligocki Pedro in them study in 2017 this work presents an efficient two-stage optimization approach to the design of steel-concrete composite I-girder bridges. In the first step, a simplified structural model, usually adopted by bridge designers, is employed aiming to locate the global optimum region and provide a starting point to the local search. Then, a finite element model (FEM) is used to refine and improve the optimization. Through this procedure, it is possible to combine the low computational cost required on the first stage with the accuracy provided on the second one [7]. Cai \& Aref (2015) studied the use of carbon fiber reinforced polymeric (CFRP) materials in the cable system of a cablestayed bridge. This work used a GA-based optimization process to improve the aerodynamics of the cable system. The analysis of the structure checked the static, dynamic and flutter performances of the bridge [8]. Kaveh et al. (2016) optimized the superstructure of post-tensioned concrete bridges using a modification of the metaheuristic algorithm Colliding Bodies Optimization (CBO). This study used 135 AASHTO and construction constraints to optimize 17 geometric design variables. The results were compared to two others optimization algorithm [9]. Also, the optimization of composite I-girder bridges developed in this dissertation was published on Pedro et al. (2017) [10].

\section{Research Methodology and Materials}

Several studies have dealt with the subject of controlling and estimating the cost of bridges in the design stages. These studies focused on the subject of cost control from the perspective of optimizing the dimensions of origin elements, where many software tools were developed that allow for the optimal design.

The cost of concrete bridges is optimized at three levels [11]:

1) Component Optimization: the most common optimization because of its ease (optimizing the cross-sectional dimensions of bridge slabs and bridges, optimizing the negative and positive reinforcement, optimizing the profiles ...etc.). 
2) Configuration or Layout Optimization: finding the optimal structure of the cross-sectional components of the bridge with the longitudinal section (the spans number, the position of the middle supports, the support type is simple or continuous, etc.). This optimization is less widespread than its predecessor.

3) System Optimization: includes optimizing the components of the bridge system as a whole, including the materials type and the overall layout of the bridge as well as the components size, this area of research is least exposed by researchers because of its difficulty and complexity.

In the area of bridge system optimization, (Aparicio et al., 1996) developed a computer-aided design system for prestressed concrete road bridges provides the essential engineering data with full engineering dimensions, the material quantities and the cost of all the bridge components [12]. (Cohnet al, 1993) proposed a system of superstructure design for the small- and medium-span of road bridges using nonlinear programming methods to obtain the lowest cost of the bridge superstructure as a criterion for optimization [13].

As for the estimation of preliminary bridges cost, which is a cost control tool, studies of (Fragkakis \& Lambropoulos, 2004) and (Menn, 1990) have adopted on statistical methods to find a model for estimating the quantities and the cost of concrete bridges. The artificial intelligence methods were also used in cost estimation. (Creese et al., 1995) used the neural network to estimate the cost of the wooden bridges [14].

This research will attempt to propose a cost control approach that fits within the framework of optimizing the bridge system as a whole. This approach is based on the unitary price (UP) method for cost estimation, where the quantities are estimated as parameters while the prices are determined from a guide that is updated periodically.

It should be noted that the field of study will be around the slabs of reinforced and pre-stressed concrete bridges.

\subsection{Method Used to Control the Cost of Concrete Bridge}

The proposed cost control methodology states selecting a solution for each component of the origin from a range of technically feasible solutions (alternatives) and based on available data of origin (project characteristics)

After selecting the technical solution of the component, its cost is estimated based on the parametric estimation method adopted, which is based on the cost estimation from quantities parametrically estimated and prices adopted and updated periodically.

Thus moving from one component to another until reaching the last component of the origin. Then the cost is compared to the potential budget of the owner to mobilize for completing the project; either the cost is lower than the budget. Therefore the options that are selected for each element are valid, and the design is acceptable, or the cost of origin is larger than the budget where in this case and after analyzing why the cost exceeded the budget, and the extent of this exceeding, modifications to the initial design are suggested and return to the evaluation and comparison until reaching a solution that achieves the economic condition. Figure 1 illustrates the proposed methodology.

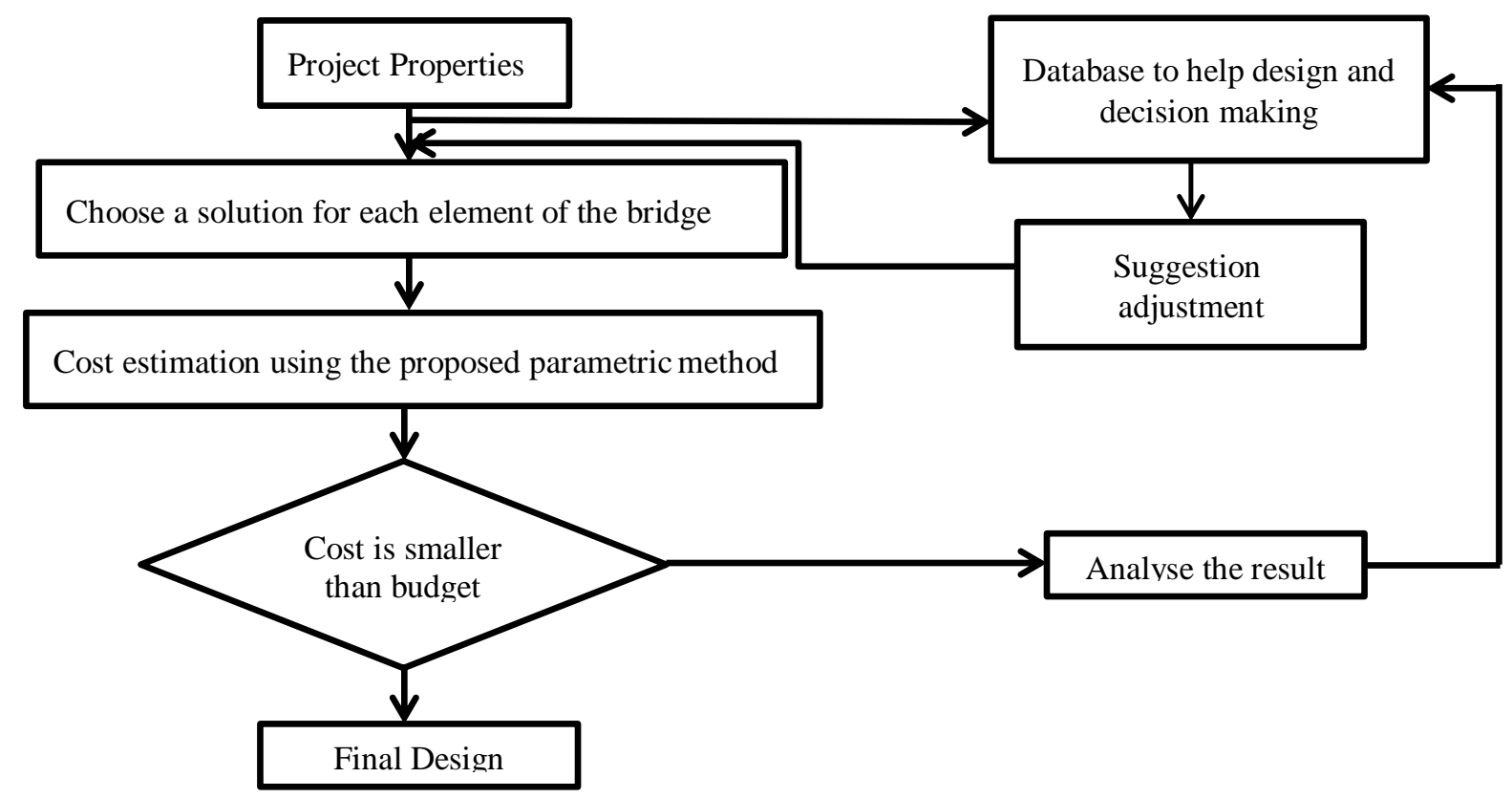

Figure 1. Suggested methodology to help design with cost control

In summary, the outline of the cost control methodology as follows: 
1) Defining technical solutions (alternatives) for each component of the origin.

2) Estimating the quantities of items for each of the components concerning each of the alternatives through the developing parametric relations between the quantities of the item with the appropriate parameter.

3) Defining the items price.

4) Estimating the cost for each alternative.

\section{Results and Discussion}

The previously proposed methodology is applied to help design and then propose a database filled in by information collected from all the various bridges projects at a broader level for all studies in this field.

\subsection{The Application of the Proposed Cost Control Methodology:}

The SPSS program has the ability to carry out a wide variety of statistical operations, in which it is possible to classify and control both quantitative and descriptive data, as well as the use of advanced statistical analyzes such as statistical modelling and reasoning.

This is done in the form of pre-prepared orders that facilitate the use process, in addition to the availability of auxiliary instructions that are comprehensive and clear.

In this paper, most of the SPSS processes will be used in data handling, characterization, import and export. Data will be modified and computed, quantitative and descriptive variables will be converted, and data will be distributed in pivotal and repetitive tables.

The method of summarizing statistical data through pivot tables is a semi-necessary tool for any statistical analysis, and binary pivot tables are the most widely used form, especially when it is about measuring the relationship between two variables.

\subsubsection{Defining the Alternatives of the Bridge Components}

This constitutes the first step in the methodology of cost control where the technical solutions are defined for each element according to each type of bridges. It should be noted that the documents used during this phase are the references of bridges design as well as the files of designing the bridges carried out within the capital Sana'a bridges project (12 bridges) and those carried out in Sana'a-Aden road (7 bridges). For example, four alternatives for the bridge slab component were defined as:

- (S. 1) Distributed inertia slab.

- (S. 2) Distributed inertia and pre-stressed hollow slab.

- (S. 3) Central-spine with side cantilevers hollow slab.

- (S. 4) Slab with Longitudinal Girder Linked by Continuous Slab.

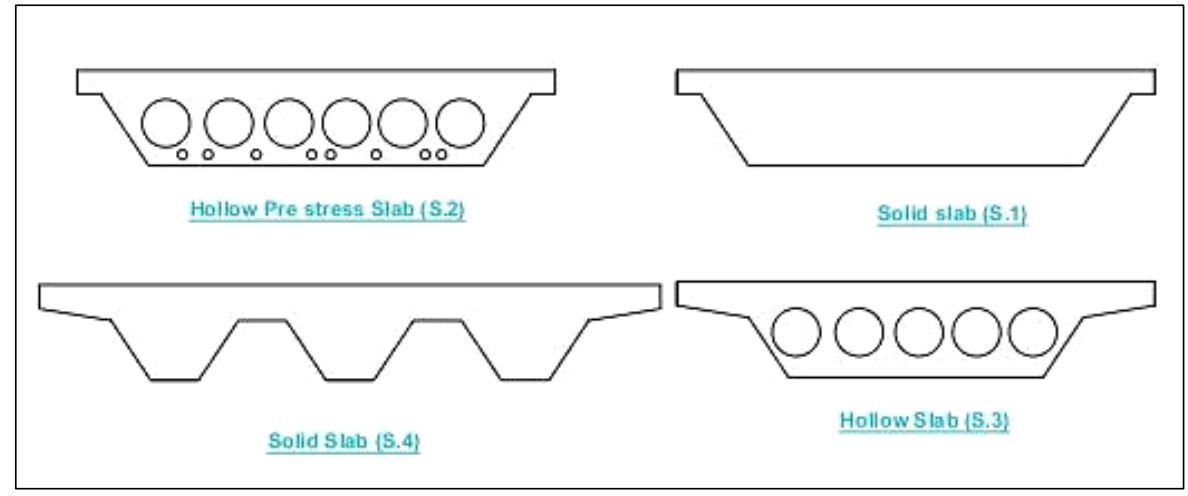

Figure 2. Shows the cross-section of these four types of bridge slabs

\subsubsection{Developing a Model for Estimating the Number of Bridge Works}

This phase aims at developing mathematical models to estimate the quantity of each item of the origin component. These models link between the quantity of the item and parameters called quantity determinants. General parameters were adopted which form the data available during the early design (bridge length, bridge width, free height, number of spans, length of the maximum span, the height of the edge support). Other parameters derived from the general parameters (bridge area, the height of the edge support $\times$ bridge width, bridge height $\times$ bridge width, etc.) were also 
defined.

The decline analysis technique was chosen for finding the mathematical formulas because it is an excellent way to formulate the relationship between the quantity of the components items and the parameters of the project. The following summarizes the primary stages of developing the model of bridge works quantities:

1) Assuming the form of the declining model:

The linear form of the declining model is assumed so that its general form takes the following equation:

$y_{i}=\beta_{0}+\beta_{1} x_{i}$

Where:

$y_{i}$ : The amount of work (e.g. the amount of concrete work for the solid slab).

$x_{i}$ : An index of amount of work number (i) $(\mathrm{i}=1,2,3 \ldots 12)$ it is called the variable explained or predicted.

$\beta_{0}$ : Constant reflects the cut part (intercept) of the vertical axis which is an average value of the variable function. When $x_{i}=0$

$\beta_{1}$ is the slope of the straight line, expresses the amount of change in the amount of work if there has been a change in the amount index by one unit, and is also called the decline coefficient, the type of its sign indicates whether there is positive or reverse impact of the quantity index on the amount of work.

2) Using the least squares method (Ordinary Least Squares (OLS))

To estimate the model parameters $\beta_{1}, \beta_{0}$ and then estimate the model $\hat{y}_{i}=\hat{\beta}_{0}+\hat{\beta}_{1} x_{i}$..

3) The use of the indicative statistic

In the test of the validity of the model in the representation of the relationship between the quantity of work and the determinant of the amount of its work, as well as in the test of the significance of the parameters of the model.

The value of $R^{2}$ was used as an indicator of model quality, which measures the intensity of the relationship between the quantity of work and its quantity determinants, which is always positive and shows the proportion of changes in the $y$ variable that can be returned to the declivity. If this coefficient is large, this indicates the quality of the model.

To test the validity of the model, test the hypothesis of a real linear relationship between the variables, the test function $F$ is usually used, which represents the ratio between the mean squares indicating the decline to the average of the error square. Therefore, for the linear relationship to be real and significant, the value of $\mathrm{F}$ and the value of (Sig (P-Value)) should be minimal, depending on the level of significance determined by the researcher, and the most significant level is used $(\alpha=0.01, \alpha=0.05)$.

To test the significance of the model transactions, the following decision criteria were adopted:

(P-Value 00.05) The zero hypotheses is rejected

(P-Value> 0.05) The zero hypotheses is accepted

It should be noted here that the rule on which model variables are chosen should not be based solely on Statistical Logic, but logical and theoretical questions must be taken into consideration [15].

The previous steps were adopted by adopting the statistical program (SPSS) as a specialized program in this filed. Where the data set of the quantity of elements items (15) bridges with specific quantitative data for each item quantity was entered into this program. Since the value of the quantity of work takes the value of zero when the value of the specified quantity is null, therefore, the simple linear model passed from the principle was adopted, which can be achieved through the (SPSS) program by making the value of the constant $\left(\beta_{0}\right)$ in the model is null, and then the statistical measurements for each model $\left(R^{2}\right.$, P-Value or Sig) were obtained [16].

The outputs are shown in Figure 5 for the tile mass data set (S.1), and the bridge area was obtained. Table (1.a.b.c) Outputs of the analysis by adopting the statistical program and the amount of concrete slab (S.1)

Table (1.a, b, c) shows the models resulting from the statistical program SPSS, which link the amount of work to the work quantity parameter, for alternatives to the slab element. Area of Bridge is the independent variable.

Table 1a. Linear Model Summary*

\begin{tabular}{cccc}
\hline $\mathbf{R}$ & $\mathbf{R}^{\mathbf{2}}$ & Adjusted $\boldsymbol{R}^{\mathbf{2}}$ & Std. Error of the Estimate \\
\hline 0.997 & 0.994 & 0.993 & 35.040 \\
\hline * The equation was estimated without the constant term.
\end{tabular}

* The equation was estimated without the constant term. 
Table 2a. ANOVA*

\begin{tabular}{cccccc}
\hline & Sum of Squares & df & Mean Square & F & Sig. \\
\hline Decline & 3113580.606 & 1 & 3113580.606 & 2535.831 & 0.000 \\
Residual & 19645.348 & 16 & 1227.834 & & \\
\hline Total & 3133225.954 & 17 & & & \\
\hline
\end{tabular}

* The equation was estimated without the constant term.

Table 1c. Coefficients

\begin{tabular}{ccccccc}
\hline & \multicolumn{2}{c}{ Unstandardized Coefficients } & \multicolumn{2}{c}{ Standardized Coefficients } & \multirow{2}{*}{ t } & \multirow{2}{*}{ Sig. } \\
\cline { 2 - 4 } & B & Std. Error & Beta & & \\
\hline Area of Bridge & 0.728 & 0.014 & 0.997 & 50.357 & 0.000 \\
\hline
\end{tabular}

Table 2. The dependent $y$ for the amount of concrete slab to Component of concrete bridges

\begin{tabular}{ccc}
\hline The dependent variable $\mathbf{y}$ & Independent variable X Quantity Limit & $\begin{array}{c}\text { Decline Equation } \\
\mathbf{y}=\boldsymbol{\beta}_{\mathbf{1}} \boldsymbol{x}\end{array}$ \\
\hline The quantity of Concrete slab $\left(\mathrm{m}^{3}\right)(\mathrm{S} .1)$ & Area of Bridge $\left(\mathrm{m}^{2}\right)$ & $\mathrm{y}=0.728 x$ \\
The quantity of Steel slab $(\mathrm{Kg})(\mathrm{S} .1)$ & Area of Bridge $\left(\mathrm{m}^{2}\right)$ & $\mathrm{y}=157.644 x$ \\
The quantity of Concrete slab $\left(\mathrm{m}^{3}\right)(\mathrm{S} .2)$ & Maximum Span *Area of Bridge $\left(\mathrm{m}^{2}\right)$ & $\mathrm{y}=0.027 x$ \\
The quantity of Steel slab $(\mathrm{Kg})(\mathrm{S} .2)$ & Maximum Span *Area of Bridge $\left(\mathrm{m}^{2}\right)$ & $\mathrm{y}=6.138 x$ \\
The quantity of Cable slab $(\mathrm{Kg})(\mathrm{S} .2)$ & Maximum Span *Area of Bridge $\left(\mathrm{m}^{2}\right)$ & $\mathrm{y}=0.861 x$ \\
The quantity of Concrete slab $\left(\mathrm{m}^{3}\right)(\mathrm{S} .3)$ & Area of Bridge $\left(\mathrm{m}^{2}\right)$ & $\mathrm{y}=0.693 x$ \\
The quantity of Steel slab $(\mathrm{Kg})(\mathrm{S} .3)$ & Area of Bridge $\left(\mathrm{m}^{2}\right)$ & $\mathrm{y}=205.617 x$ \\
The quantity of Concrete slab $\left(\mathrm{m}^{3}\right)(\mathrm{S} .4)$ & Area of Bridge $\left(\mathrm{m}^{2}\right)$ & $\mathrm{y}=0.827 x$ \\
The quantity of Steel slab $(\mathrm{Kg})(\mathrm{S} .4)$ & Area of Bridge $\left(\mathrm{m}^{2}\right)$ & $\mathrm{y}=207.995 x$ \\
\hline
\end{tabular}

\subsubsection{Setting the Limits of the Model}

The form was usually prepared through a specific set of data. This model is valid for the field of data used, and therefore the use of the model to perform the extrapolation process must be done very carefully outside the data area.

In fact, it is not possible to determine whether the decline line will maintain its path outside the data field or that it will take another direction [17].

Table 3 shows the data field of the substrate models of the slab element, for which the model is valid.

Table.3 Field of data on models of substitutive element Slab

\begin{tabular}{|c|c|c|c|}
\hline The dependent variable $y$ & $\begin{array}{c}\text { Independent variable X Quantity } \\
\text { Limit }\end{array}$ & $\begin{array}{c}\text { Decline Equation } \\
\qquad y=\beta_{1} x \\
\end{array}$ & $\begin{array}{c}\text { Data area } \\
{[\mathrm{X} 1, \mathrm{X} 2]} \\
\end{array}$ \\
\hline The quantity of Concrete slab $\left(\mathrm{m}^{3}\right)(\mathrm{S} .1)$ & Area of Bridge $\left(\mathrm{m}^{2}\right)$ & $\mathrm{y}=0.728 x$ & {$[916-310]$} \\
\hline The quantity of Steel slab (Kg) (S.1) & Area of Bridge $\left(\mathrm{m}^{2}\right)$ & $\mathrm{y}=157.644 x$ & {$[916-310]$} \\
\hline The quantity of Concrete slab $\left(\mathrm{m}^{3}\right)(\mathrm{S} .2)$ & Maximum Span *Area of Bridge $\left(\mathrm{m}^{2}\right)$ & $\mathrm{y}=0.027 x$ & {$[30079-70831]$} \\
\hline The quantity of Steel slab (Kg) (S.2) & Maximum Span *Area of Bridge $\left(\mathrm{m}^{2}\right)$ & $y=6.138 x$ & {$[30079-70831]$} \\
\hline The quantity of Cable slab (Kg) (S.2) & Maximum Span *Area of Bridge $\left(\mathrm{m}^{2}\right)$ & $\mathrm{y}=0.861 x$ & {$[30079-70831]$} \\
\hline The quantity of Concrete slab $\left(\mathrm{m}^{3}\right)(\mathrm{S} .3)$ & Area of Bridge $\left(\mathrm{m}^{2}\right)$ & $\mathrm{y}=0.693 x$ & {$[2221-324]$} \\
\hline The quantity of Steel slab (Kg) (S.3) & Area of Bridge $\left(\mathrm{m}^{2}\right)$ & $y=205.617 x$ & {$[2221-324]$} \\
\hline The quantity of Concrete slab $\left(\mathrm{m}^{3}\right)(\mathrm{S} .4)$ & Area of Bridge $\left(\mathrm{m}^{2}\right)$ & $\mathrm{y}=0.827 x$ & {$[3240-1056]$} \\
\hline The quantity of Steel slab (Kg) (S.4) & Area of Bridge $\left(\mathrm{m}^{2}\right)$ & $\mathrm{y}=207.995 x$ & {$[3240-1056]$} \\
\hline
\end{tabular}

\subsubsection{Definition of Item Prices}

The prices for each item of the bridge elements were defined using the road and bridge price analysis manual issued by the Ministry of Public Works and Roads in 2009. It should be noted that these prices can be updated periodically.

\subsubsection{Cost Estimate}

The unit price method (UP) was adopted as a method for estimating the cost of bridges. The quantities are estimated from the parametric models that were taken and the prices of the "Price and Bridge Analysis Manual" issued by the 
Ministry of Public Works and Roads.

To verify the reliability of this method and the accuracy of the models developed, we tested this method on a sample of bridges (6 bridges) whose data were not used during the development of parametric models to estimate quantities.

In fact, the accuracy of the method used to estimate the cost of the size and type of data used is, in other words, the stage of the project definition (Creedy, 2006). Table 4 shows the accuracy of the cost estimate by design stage.

Table 4. Field of data on models of substitutive element Slab

\begin{tabular}{ccc}
\hline Estimate Type & Project Development & Expected Percent Error \\
\hline Conceptual & Programming and Schematic Design & {$[-10,+40] \%$} \\
Semi-Detailed & Design Development & {$[-5,+25] \%$} \\
Detailed & Final Design & {$[-3,+10] \%$} \\
\hline
\end{tabular}

Tables 5 to 7 show the data and results of the cost estimation and the accuracy of the estimation of the parametric method developed under this research.

Table 5. Bridge data for the test sample

\begin{tabular}{|c|c|c|c|c|c|c|c|}
\hline Bridge & $\begin{array}{c}\text { Length of } \\
\text { Bridge (m) }\end{array}$ & $\begin{array}{c}\text { Width of } \\
\text { Bridge }(\mathbf{m})\end{array}$ & $\begin{array}{c}\text { Height of } \\
\text { Bridge }(\mathrm{m})\end{array}$ & $\begin{array}{c}\text { Length of Maximum } \\
\text { Span (m) }\end{array}$ & No. of Span & $\begin{array}{c}\text { Height of } \\
\text { Support } 1(\mathrm{~m})\end{array}$ & $\begin{array}{c}\text { Height of } \\
\text { Support } 2(\mathrm{~m})\end{array}$ \\
\hline B51 & 54.85 & 6 & 6 & 17.6 & 4 & 7.32 & 7.32 \\
\hline B99 & 54.34 & 12.6 & 5.88 & 13 & 4 & 3.5 & 3.5 \\
\hline B85 & 59.4 & 12.5 & 6.58 & 20.05 & 4 & 10.1 & 11 \\
\hline B96 & 69.36 & 17.8 & 6 & 20.8 & 4 & 11.9 & 7.92 \\
\hline B121 & 18 & 18.75 & 6.7 & 18.75 & 1 & 8.44 & 8.44 \\
\hline B12 & 100 & 13 & 7 & 20 & 5 & 10.5 & 11.5 \\
\hline
\end{tabular}

Table 6. The initial estimate of the amount of primary work of the B99 Bridge of the test sample

\begin{tabular}{cccc}
\hline Bridge & Item & Actual quantity & Quantity calculated \\
\hline & The quantity of Concrete slab $\left(\mathrm{m}^{3}\right)(\mathrm{S} .1)$ & 528.94 & 498.45 \\
The quantity of Steel slab $(\mathrm{Kg})(\mathrm{S} .1)$ & 110152.00 & 107936.32 \\
& The quantity of Concrete for Middle Support P.2 $\left(\mathrm{m}^{3}\right)$ & 47.63 & 45.86 \\
& The quantity of Steel for Middle Support P.2 $(\mathrm{Kg})(\mathrm{S} .1)$ & 6347.67 & 6006.38 \\
& The quantity of Concrete for Edge Support A.2 $\left(\mathrm{m}^{3}\right)$ & 78.67 & 81.65 \\
& The quantity of Steel for Edge Support A.2 $(\mathrm{Kg})(\mathrm{S} .1)$ & 12546.62 & 10181.20 \\
& The quantity of Concrete for Edge Support A.2 $\left(\mathrm{m}^{3}\right)$ & 74.42 & 83.35 \\
& The quantity of Steel for Edge Support A.2 $(\mathrm{Kg})(\mathrm{S} .1)$ & 13914.38 & 51.35 \\
The quantity of Plain Concrete $\left(\mathrm{m}^{3}\right)$ & 58.99 & 513.51 \\
& The quantity of Concrete for Foundation $\left(\mathrm{m}^{3}\right)$ & 910.57 & 55886.65 \\
The quantity of Steel for Foundation $(\mathrm{Kg})$ & 76168.00 & 2197.84 \\
\hline
\end{tabular}

Table 7. The degree of accuracy of the initial estimate of the cost of the main work of sample test bridges

\begin{tabular}{cccc}
\hline Bridge & $\begin{array}{c}\text { The cost resulting from estimated } \\
\text { quantities (YE.R) }\end{array}$ & $\begin{array}{c}\text { The cost of Cost resulting from } \\
\text { actual quantities (YE.R) }\end{array}$ & Accuracy \% \\
\hline B51 & 888255600 & 972551056 & $-9.49 \%$ \\
B99 & 2654399231 & 2220670397 & $16.34 \%$ \\
B85 & 3956764132 & 3404004183 & $13.97 \%$ \\
B96 & 2431876056 & 2514316654 & $-3.39 \%$ \\
B121 & 1856743178 & 1522900755 & $17.98 \%$ \\
B12 & 2876987560 & 3110311251 & $-8.11 \%$ \\
\hline
\end{tabular}

It can be seen from Table (7) that the proposed models for estimating the initial cost have given good results within the accuracy of $[-10,+40]$. 


\subsection{Proposed Cost Control Database}

The stages of a database design can be divided into three phases: knowledge modeling, database structure design, database provisioning.

\subsubsection{Knowledge Modelling}

Modelling leads to the development of models to estimate the cost of concrete bridges and to dedicate and compile expertise in this filed rather than remain in the minds of some cadres and experts working within the implementation companies [18].

The modeling language (NIAMNijssen's Information Analysis Method) is used to represent schemas as a simple language based on three concepts: the entity that is represented by an ellipse or a circle that writes the name of the entity within it.

The relationship is a link between two entities represented by a rectangle divided into two parts: left and right. Each section follows the entity on its side, the constraint that defines the conditionality of the relationship between entities. We distinguish between two kinds of entity constraints: Constraint Inclusiveness, symbolized by (V), and constrained Unity, and symbolized by (.).

Figure (3) shows the model of bridge works consisting of principal works and secondary works. Figure 4 illustrates the model of the bridge elements, where each element has an alternative form, technology, implementation option, and cost.

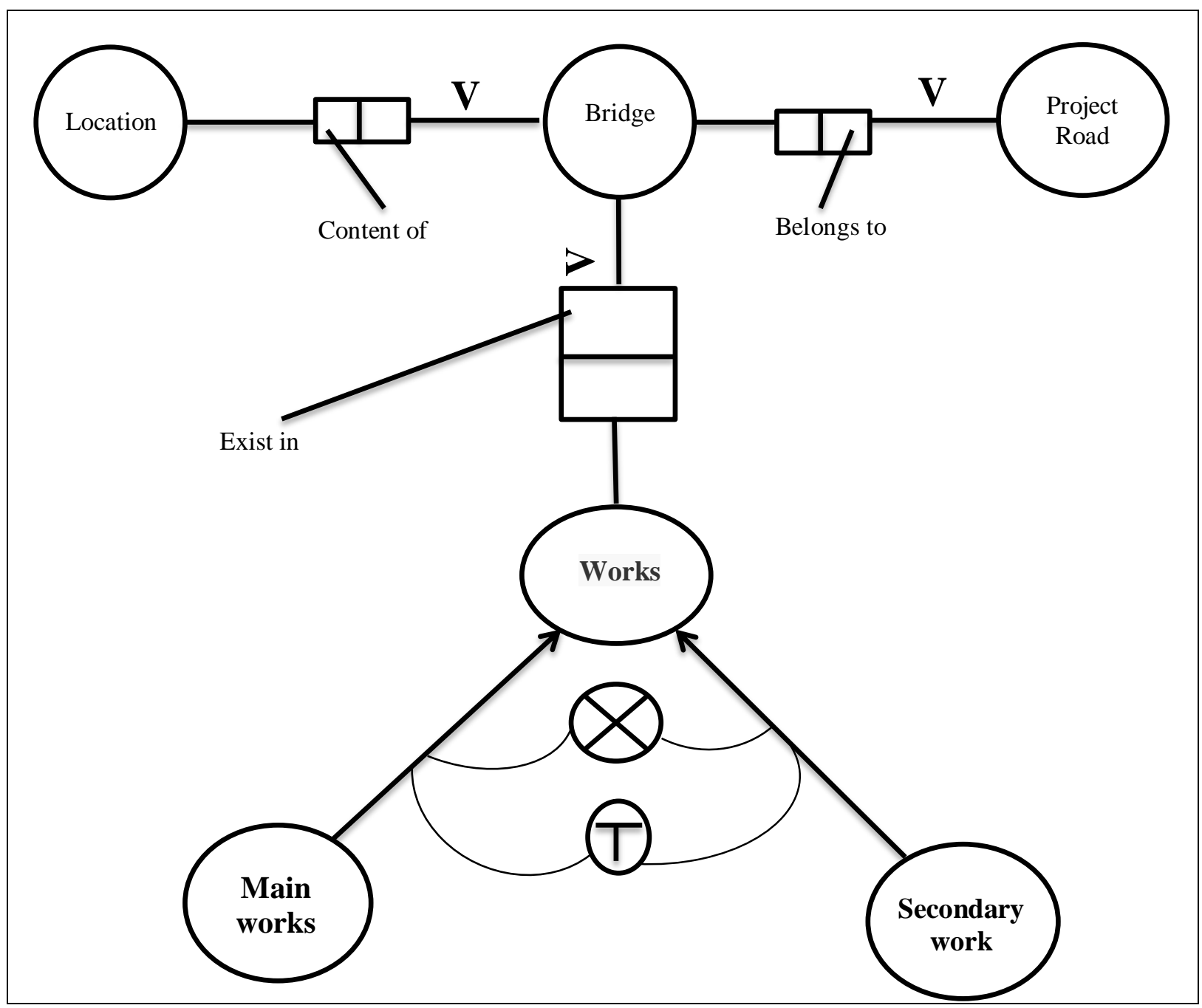

Figure 3. Works Model 


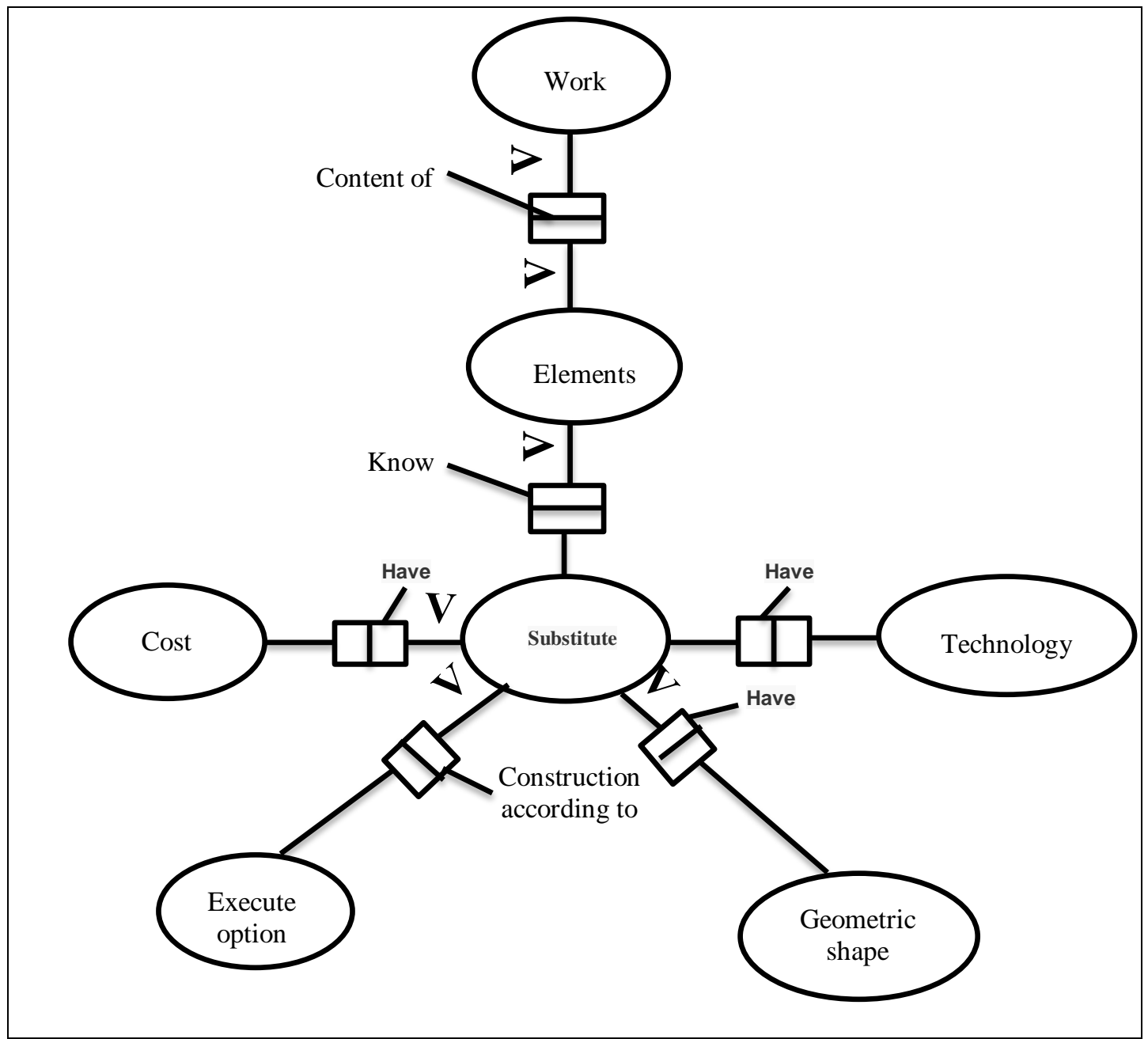

Figure 4. Show the cost model for the bridge facility where the cost consists of direct cost and indirect cost and our research is concerned with the direct cost of the component 


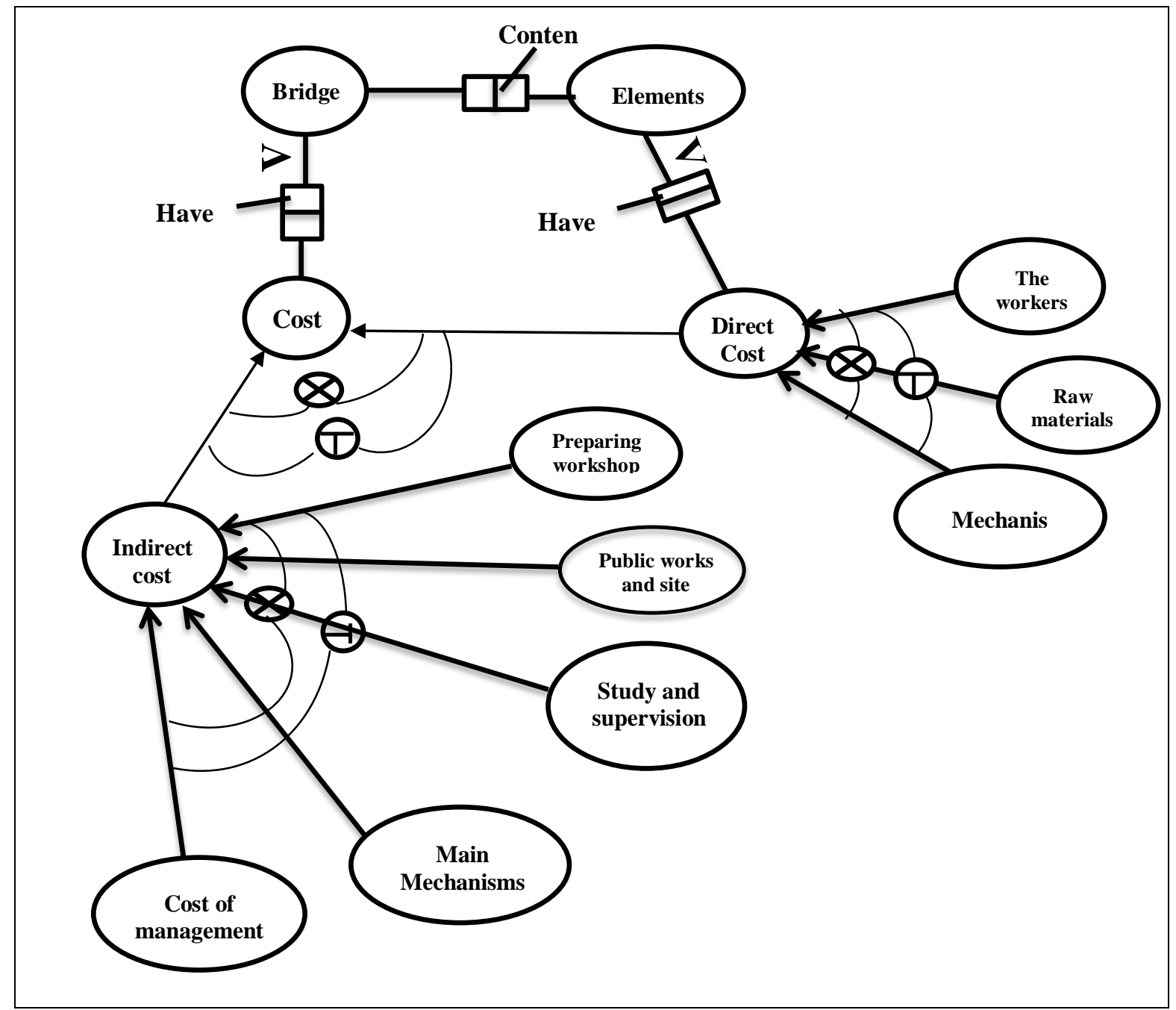

Figure 5. Cost Model

\subsubsection{Database Structural Design}

Based on the models previously presented, a database structure was designed to control the cost of concrete bridge projects. This structure consists of a set of two-dimensional tables (properties, values) that translate the links between a set of values.

Figure 6 shows the proposed structure of the cost control database for concrete bridge projects.

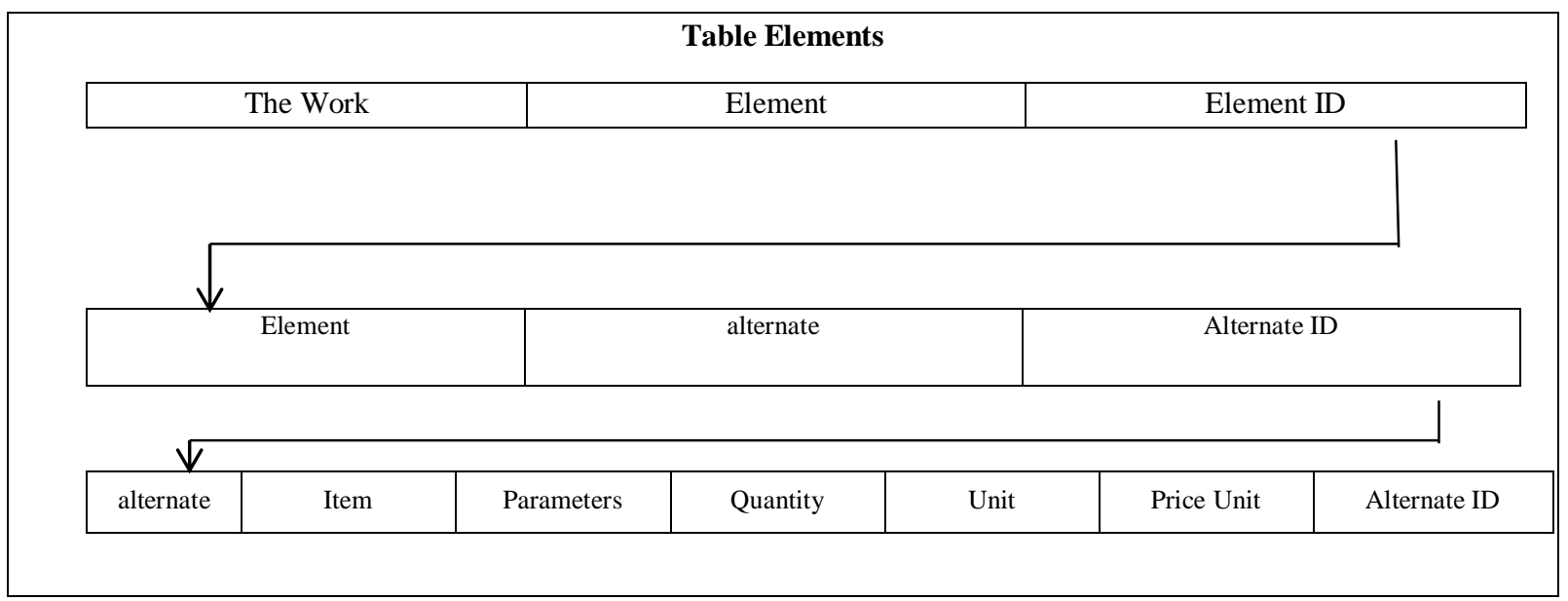

Figure.6 Proposed database structures

Explanation of the previous database tables will be doing a simple example of one type of works:

Table of Elements: Elements of the principal works are included in concrete bridge projects and are composed of the following fields: 
Element: This field identifies the elements that make up the project.

Definition of Item Code: Each element is encoded to be the reference code for the element in the subsequent table.

The Table 8 shows the primary works of the bridge elements

Table 8. Table of Element

\begin{tabular}{cc}
\hline Element & Code definition of element \\
\hline Slabs & $\mathrm{S}$ \\
Edge Supports & $\mathrm{A}$ \\
Middle Supports & $\mathrm{P}$ \\
Foundation & $\mathrm{F}$ \\
Excavation & $\mathrm{E}$ \\
\hline
\end{tabular}

Alternatives Table: Alternatives to a specific item and composed from the following fields:

- Alternative: This field specifies the design options available for each element.

- Alternative ID: Each alternative to the element has been coded to be the reference code for the items in the subsequent table.

Table 9 shows alternatives to the edge support element.

Table 9. Table of Alternatives

\begin{tabular}{ccc}
\hline Element & Alternative & Alternative code \\
\hline A & Edge Support Abutments & A.1 \\
A & Edge Support Columns & A. 2 \\
\hline
\end{tabular}

Table of items: The items that include each alternative for a particular item consist of the following fields:

- Item: This field identifies the items that include the item.

- Distinguished parameter: This field reflects the best parameter used to approximate the quantity of each item.

- Quantity: This field expresses the parametric relationship that was derived in the previous chapter based on the statistical modelling of the data collected to calculate the quantity of each element.

-Unit: This field refers to the unit of measurement of the quantity of each element based on the parametric relationship.

-Unit Price (R.Y): This field represents the unit price for each item in Yemeni Riyals.

Table 10 shows the items that include the edge support.

Table 10. Table of Item

\begin{tabular}{cccccc}
\hline Alternative & Item & The characteristic parameter & Quantity & Unite & $\begin{array}{c}\text { Code definition } \\
\text { of item }\end{array}$ \\
\hline A.1 & Quantity of Concrete & Height of Support* Width of Bridge & $1.608^{*}$ Area of Bridge & M $^{3}$ & \\
\hline A.2 & Quantity of Steel & Height of Support * Width of Bridge & $156.79 *$ Area of Bridge & Kg & A.1.2 \\
\hline
\end{tabular}

\subsubsection{Provide Information to the Database}

The previously designed database is provided with the necessary information by collecting data, then analyzing and processing it for proper rehabilitation before entering the base.

\section{Conclusion and Recommendations}

- Conclusions: At the end of the research, the following main findings were reached:

- Suggest appropriate modelling for cost control of bridge works during design.

- Proposing an alternative cost estimation method by combining the parametric estimation method with the unit price method.

- $\quad$ Conducting a classification of bridge works within specific cost per bridge areas, this classification helps to focus on high-cost design work.

- Design a structural database to control the cost of concrete bridge projects. 
- $\quad$ Providing the database with knowledge.

- Recommendations: A set of recommendations have been identified to develop this research, which can be summarized as follows:

- $\quad$ Improve the accuracy of field data by studying a more extensive section of bridge projects (slabs).

- Mainstream the previous study on other types of bridging projects (Bridges with crosses beams etc.) to obtain databases for each type of bridge.

- Study uncertainty in estimating the initial cost of bridge projects.

- Costing and time modelling is applied together, based on both cost and time estimation of alternatives. Decision makers often ask during the cost uncertainty analysis that the project may be submitted at a given cost and time and that the estimated cost may exceed the given time.

- $\quad$ Cost control study to include various stages of the project.

\section{References}

[1] MAJID SOLAT YAVARI Slab Frame Bridges Structural Optimization Considering Investment Cost and Environmental Impacts Licentiate Thesis, (2017), KTH Royal Institute of Technology ABE- School of Architectural and the Built Environment Department of Civil and the Architectural Engineering Division of Structural Engineering and Bridges SE-100 44, Stockholm, Sweden.

[2] Sirca, Gene F., and Hojjat Adeli. "Cost Optimization of Prestressed Concrete Bridges.” Journal of Structural Engineering 131, no. 3 (March 2005): 380-388. doi:10.1061/(asce)0733-9445(2005)131:3(380).

[3] Cohn, M. Z., and Z. Lounis. “Optimal Design of Structural Concrete Bridge Systems.” Journal of Structural Engineering 120 , no. 9 (September 1994): 2653-2674. doi:10.1061/(asce)0733-9445(1994)120:9(2653).

[4] Cohn, M.Z., and G. Thiera. "Structural optimization.” Engineering Structures 19, no. 4 (April 1997): 287-288. doi:10.1016/s01410296(96)00071-5.

[5Vamsidhar, K., D. A. Eshwarswaroop, K. Ayyappapreamkrishna, and R. Gopinath. "Study and Rate Analysis of Escalation in Construction Industry.” IOSR Journal of Mechanical and Civil Engineering 11, no. 2 (2014): 14-25. doi:10.9790/1684-11251425.

[6] Jrade, Ahmad, and Julien Lessard. "An Integrated BIM System to Track the Time and Cost of Construction Projects: A Case Study.” Journal of Construction Engineering 2015 (2015): 1-10. doi:10.1155/2015/579486.

[7] Renata Ligocki Pedro "Optimization of Steel-Concrete Composite I-Girder Bridges" the Federal University of Santa Catarina, Brazil, 2017.

[8] Cai, Hongwei, and Amjad J. Aref. "On the Design and Optimization of Hybrid Carbon Fiber Reinforced Polymer-Steel Cable System for Cable-Stayed Bridges.” Composites Part B: Engineering 68 (January 2015): 146-152. doi:10.1016/j.compositesb.2014.08.031.

[9] Kaveh, A., M. Maniat, and M. Arab Naeini. "Cost Optimum Design of Post-Tensioned Concrete Bridges Using a Modified Colliding Bodies Optimization Algorithm." Advances in Engineering Software 98 (August 2016): 12-22. doi:10.1016/j.advengsoft.2016.03.003.

[10] Pedro, R.L., J. Demarche, L.F.F. Miguel, and R.H. Lopez. “An Efficient Approach for the Optimization of Simply Supported Steel-Concrete Composite I-Girder Bridges." Advances in Engineering Software 112 (October 2017): 31-45. doi:10.1016/j.advengsoft.2017.06.009.

[11] Hassanain, Mostafa A, and Robert E Loov. "Cost Optimization of Concrete Bridge Infrastructure." Canadian Journal of Civil Engineering 30, no. 5 (October 2003): 841-849. doi:10.1139/103-045.

[12] Aparicio, A.C., J.R. Casas, and G. Ramos. "Computer Aided Design of Prestressed Concrete Highway Bridges.” Computers \& Structures 60, no. 6 (July 1996): 957-969. doi:10.1016/0045-7949(96)00033-8.

[13] Cohn, M. Z., and Z. Lounis. “Optimal Design of Structural Concrete Bridge Systems.” Journal of Structural Engineering 120, no. 9 (September 1994): 2653-2674. doi:10.1061/(asce)0733-9445(1994)120:9(2653).

[14] Fragkakis, N. P., and S. Lambropoulos. "A quantity and cost estimate model for concrete road bridges." Tech. Chron. Science Journal, TCG 1 (2004): 24.

[15] PHAOBUNJONG, K. Parametric Cost Estimating Model for Conceptual Cost Estimating of Building Construction Projects.In partial fulfillment of the requirements for the degree of Doctor of philosophy, University of Texas, Austin, (2002) .203.

[16] Hakim, Ibrahim, SPSS reference in the analysis of data. First Edition, Shuaa Publishing, and Science, Syria, 527, (2004).

[17] Creedy, D. G. Risk Factors Leading To Cost Overrun in The Delivery of Highway Construction Projects. Ph.D. Dissertation, University of Technology, Australia, (2006), 244.

[18] Bernus, P.; Mertins, K.; Gunter, S.Handbook on Architectures of Information System, Business, and Economics, U.S.A., (2006), 896. 